ISSN: 2277-3754

ISO 9001:2008 Certified

International Journal of Engineering and Innovative Technology (IJEIT)

Volume 10, Issue 11, May 2021

\title{
Regional Assessment of Ozone across Nigeria, from 2005 to 2018 using NASAGIOVANNI Air Quality
}

\author{
David-Okoro I.L*., Chineke T.C., Nwofor O.K, Mbagwu JP.C and Ewurum N.B.B \\ Imo State University, Owerri, Nigeria
}

\begin{abstract}
Nigeria is a developing country situated in West Africa. As a developing, country, it is experiencing critical problem such as insecurity, political,social and religious crisis to mention but a few. Nigeria is equally urbanizing very fast and as such is overwhelmed with problems emanating from urbanisation, industrialization and agricultural development. These anthropogenic encumberances grossly inhibitthe country from effectively paying attention toperennial problem like air pollution. Ground level ozone was studied from NASA Giovanni air quality platform from 2005 to 2018. Visualizations from this study, shows an indication of seasonal fluctuations of ozone. The highest annual concentration of ozone across Nigeria for the sampled years was observed in the year 2013, it recorded 269.7DU. Others years include 2015, 2014, 2008 and 2004 they recorded $268.69 \mathrm{DU}, 267.31 \mathrm{DU}, 267.19 \mathrm{DU}$ and $265.85 \mathrm{DU}$ respectively. The least annual concentations of 260.18DU and 260.22DU were recorded in the years 2007 and 2005 respectively. A short annual range of 9.52DU was observed for the sampled years. From this study ozone decreases in the dry season and peaks in the rainy season.
\end{abstract}

Keywords: Ozone; Anthropogenic; Criteria; Pollutant; Urbanization; Industrailization.

\section{INTRODUCTION}

Nigeria is a fast developing populous country. It is deemed to have very poorly managed infrastructure [3]. The air quality in Nigeria is considered unsafe [7] [8]. This is in accordance with several independent study carried out across the country, [1] [3]. Some Research conducted on air pollution in Nigeria gave indication of air pollution exceeding WHO guidelines in some cities in Nigeria. Some of Nigeria's most greatest problems include crushing poverty, dysfunctional municipal services, and very often, political corruption. These problems tend take awaythe focus of government from providing the basic ammenities. This singular act exposes the citizens to so many anthropogenic activity that elicit air pollution. Air pollution, isseen as the contamination in air by harmful gases and particulates at a higher concentration than the natural environmental background [2] [ 4]. Some anthropogenic activities which encourageair pollutionin Nigeria include vehicle emissions, solid waste burning, use of generating sets, agriculutural biomass burning and industrial emissions to mention a few.Ground level ozone is a criteria pollutant.

Manuscript received: 27 April 2021

Manuscript received in revised form: 25 May 2021

Manuscript accepted: 10 June 2021

Manuscript Available online: 15 June 2021
Criteria pollutants are known to trigger off a lot of health challenges . Internationally, Criteria pollutant is a term used to describe air pollutants which cause havoc to health and the environment EPA.. In developed countries, ground level ozone is monitored and a red alert is often given so that the vulnerable group can stay indoors to aviod ozone pollution on red alert days by (Mecklenburg county Government, 2021). Ozone and particulate pollutants are the most widely spread health threats Department of Environmental conservation (DEC) (2021).Ozone is tri atomic oxygen. It is naturally ocuring and in abundance in the stratosphere, where it acts as a protective shield regulating the transmittance of ultraviolet radiation to Earth's Surface. In the stratosphere, ozone is referred to as "the good ozone" but in the troposphere, it is regarded as an atmospheric pollutant. Low level ozone is an unpleasant air pollutant. It is a toxic hazardous criteria pollutant in APIS, 2019. Ozone is a secondary pollutant, formed by the reaction of Nitrogen Oxides (NOx) and hydrocarbons like Volatile Organic Compounds (VOCs) under the influence of sunlight. Oxidation of volatile organic compounds (VOCs) and CO can lead to the photochemical formation of ozone [6]. It is transported hundreds of kilometers from the source of emissions. Annually in Africa, air pollution kills over 700, 000 people [8]. Casualties from air pollution in Nigeria has increased by $40 \%$ [8]. Ozone can activate a lot of health effects ranging from throat irritation, coughing and chest congestion(Mecklenburg county Government, 2021).It can also degenerate existing conditions like asthma, bronchitis and emphysema. Prolonged or constant exposure may scar lung tissuepermanently.Nigerian cities are being classified among the 30 cities in Africa with the most unhealthy air quality [8].

\section{MATERIALS AND METHOD}

Nigeria is situated in West Africa, she lies between longitude $2.5^{\circ} \mathrm{E}$ to $14.0^{\circ} \mathrm{E}$ and latitude $4.0^{\circ} \mathrm{N}$ to $14.5^{\circ} \mathrm{N}$. The neighbouring countries to the west and east are Republic of Benin and Republic of Cameroun respectively. The northern part of the country shares its boundary between Republic of Niger and Republic of Chad while the southern part of the countryflows into the Atlantic Ocean. The map of Nigeria is shown in fig.1. Daily retrivals were asssessed for ground level ozone for the concentration of Total Column Ozone across Nigeria as a region. Nigeria was assessed for Area-Averaged 


\section{IJEIT}

ISSN: 2277-3754

ISO 9001:2008 Certified

International Journal of Engineering and Innovative Technology (IJEIT)

Volume 10, Issue 11, May 2021

Ozone Total Column (DOAS) at 0.25 degree from platform,http://GIOVANNI.gsfc.nasa.gov/GIOVANNI. NASA GIOVANNI

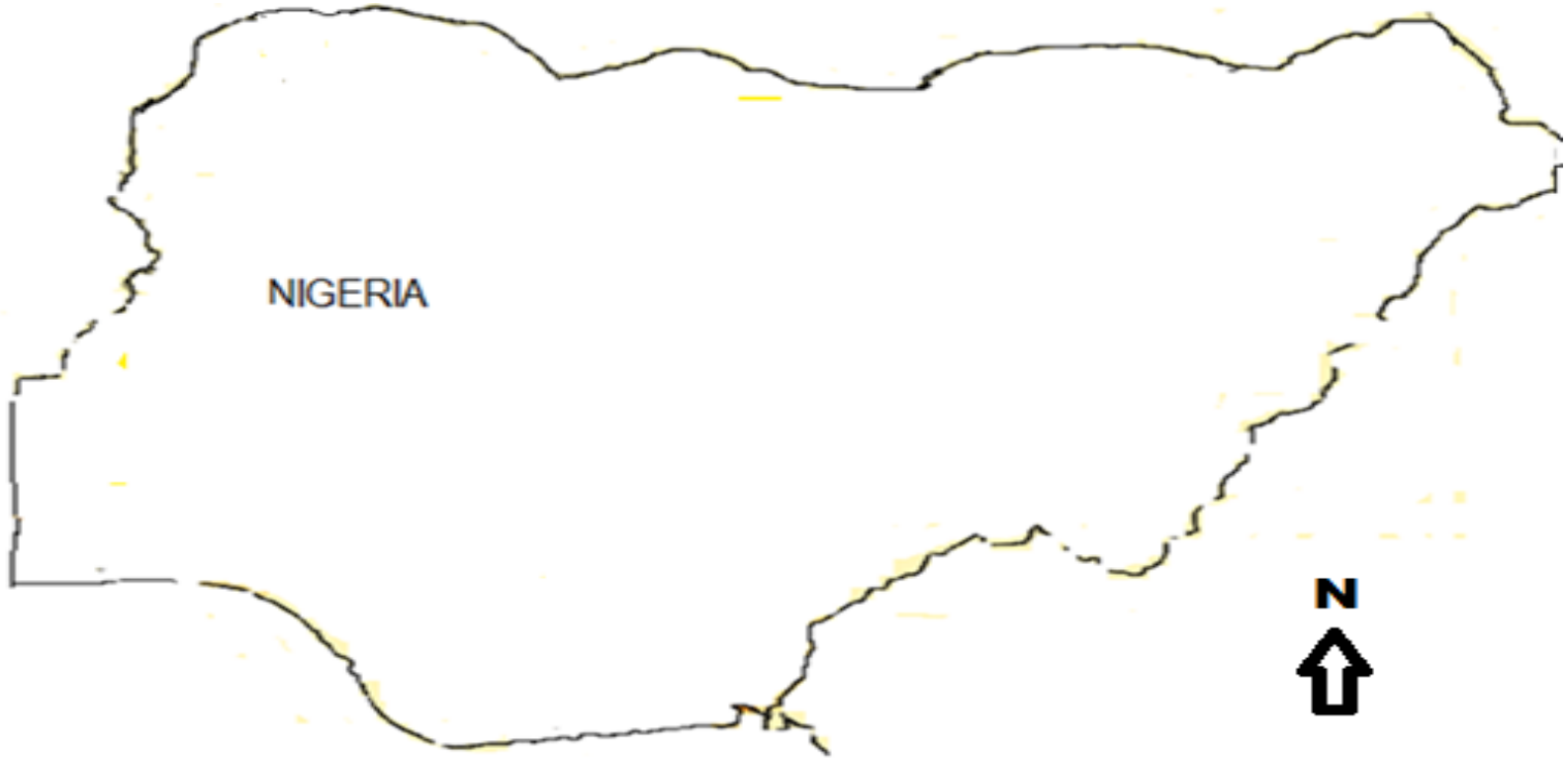

Fig.1: A map of Nigeria [3].

Simple descriptive anaysis, moving averages and regressional analysis were conducted. The moving averages of 4 and 12 were conducted and the plot is seen in figure 6. A time series graph was obtained as shown in figure 2 . The minima and maxima points depict low and high concentrations.

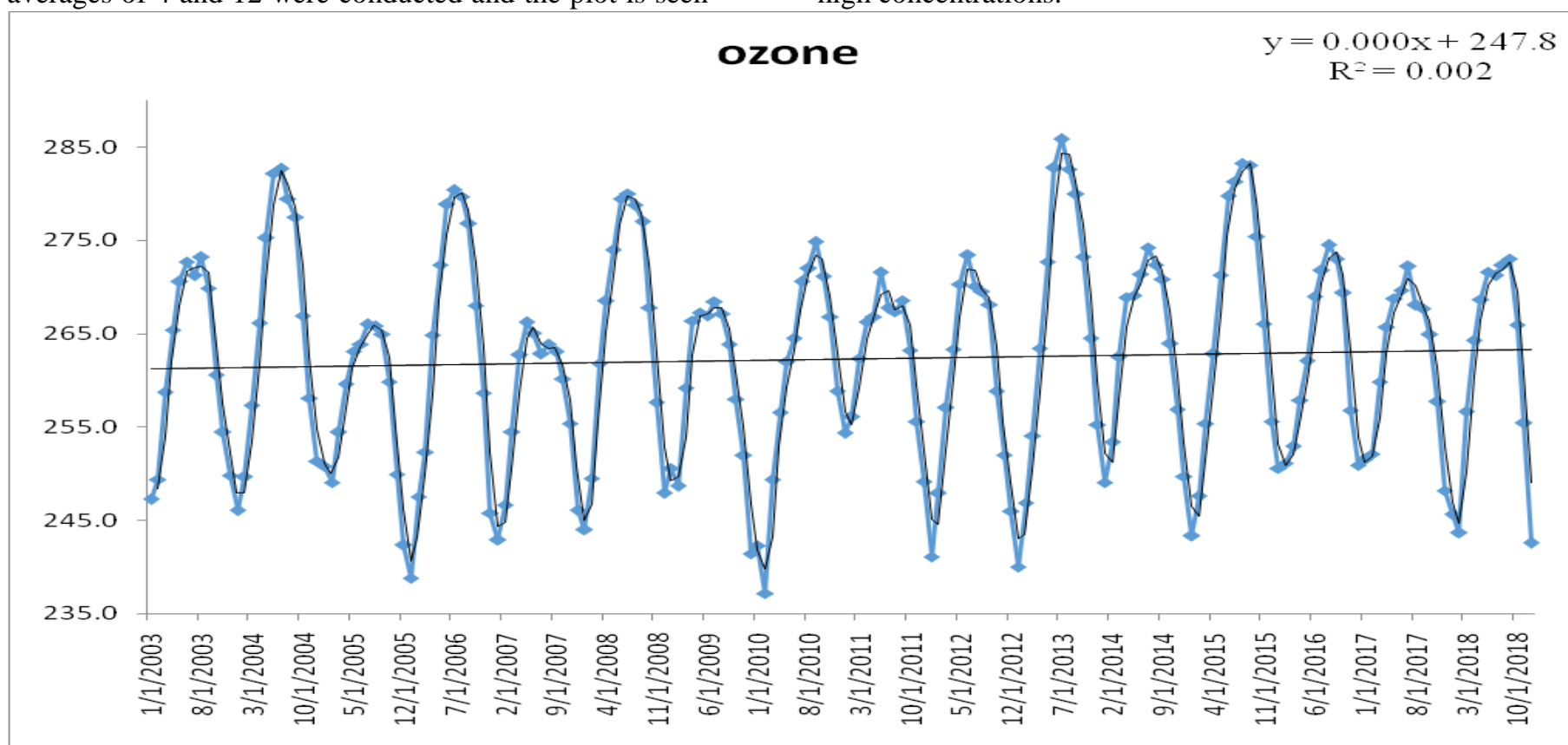

Fig. 2: Time series graph of average Total column ozone from 2005 to 2018

\section{RESULTS AND DISCUSSION}

\section{A. Concentrations of Ozone}

The least monthly concentration of ozone minima points were recorded 237.18 DU was recorded in February 2010. January, 2006, 2013, 2012 also recorded the low concentration of 238.3DU, 240.02DU, 241.11DU respectively. The highest concentration of ozone was witnessed in the months of July 2013, it recorded 285.5DU. August, 2015, June 2004, June 2008 and June
2006, recorded 283.3DU, 282.4Du, 279.5DU and 278.9DU respectivey.

\section{Secular trend}

From figure 2, the plots of the time series over Nigeria showed a regular sinusoidal time series graph for the 13 years of study. The time series showed a slight decrease from July 2006 to 2012. A maximum curvewas witnessed again in July 2013 which kept slightly decreasing till 2018. The general trend exhibited was increasing from 2005 to 2013 this implies a slight postive secular trend. 
ISSN: 2277-3754

ISO 9001:2008 Certified

International Journal of Engineering and Innovative Technology (IJEIT)

Volume 10, Issue 11, May 2021



Fig 3: Annual monthly concentration of total column Ozone for all the years

\section{Variability and Seasonality}

Figure 2 showed a regular time series with troughs and peaks appearing regularly at regular intervals for all the sampled years. This implies the presence of seasonality. A monthly graph of all the sample years showed a dome shape as seen in figure 3 .

From this figure, there is a visible increase of the plot from January to June, July or August. The plot peaks either in July or August. A visible decrease from August to December was observed for all the plots. From figure 3 , ozone decreases in the dry season and peaks in the rainy season.

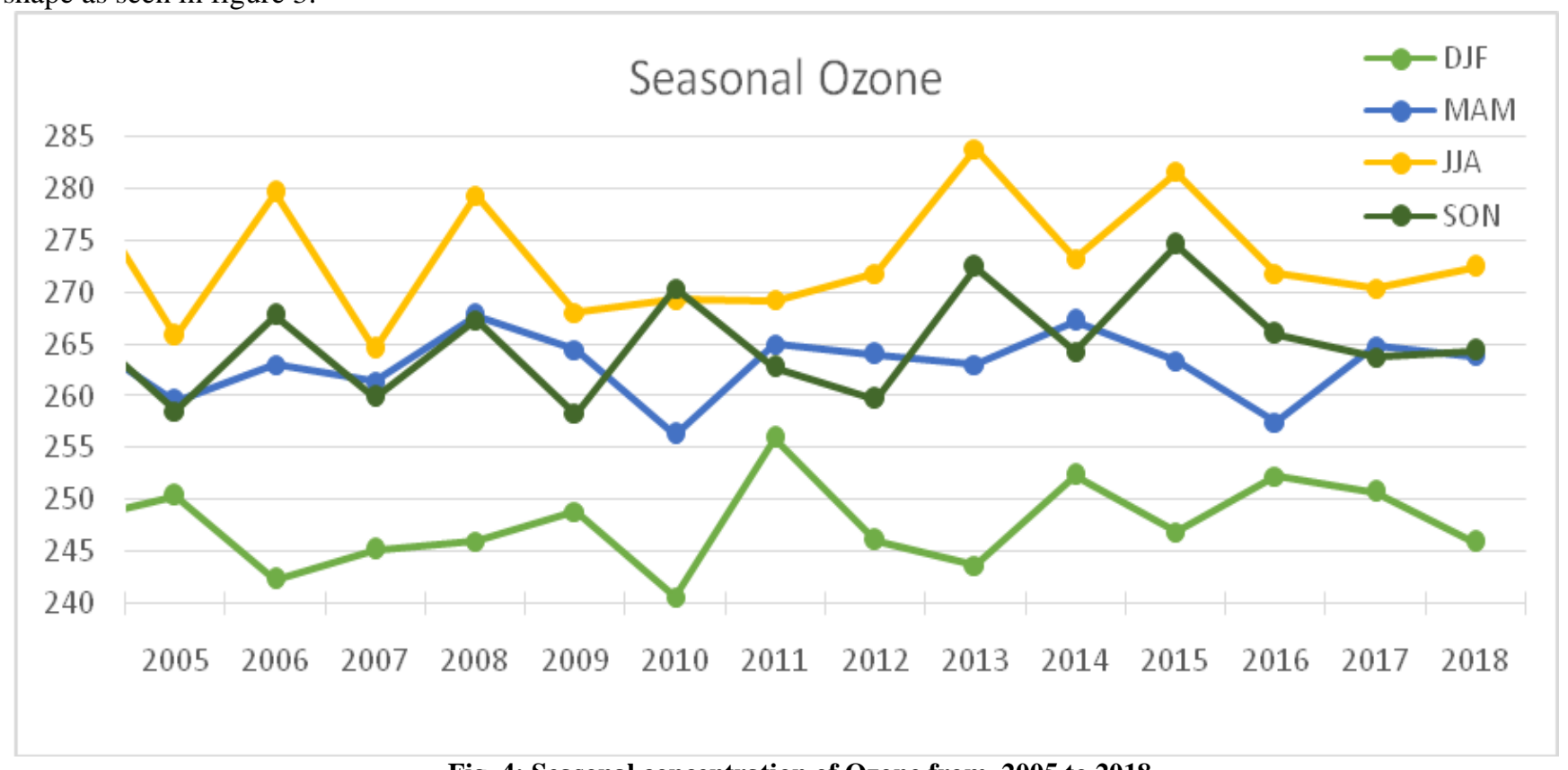

Fig. 4: Seasonal concentration of Ozone from 2005 to 2018

This can be confirmed in figure 4 June July August (JJA) recorded the highest concentration for all the years except in 2010 when September Ocober and November (SON) recorded 270.33DU while JJA recorded 269.29DU. December, January, February (DJF) recorded the least concentration for all the years. The increase in the rainy season could be due to the intense sunshine that normally preceed the rains in the rainy season. Ozone needs sunlight to form.

\section{Annual or Yearly concentration of total column Ozone}

From figure 5, for yearly concentration of ozone, the month of July recorded the highest concentrtation for most of the years. These years include 2005, 2006, 2008, 2009, 2013, 2014 and 2017. Other months which recorded the highest annual concentration were May in 2007, and September which was withnesed the highest concentrations in 2010 and 2018 respectively. 




ISSN: 2277-3754

ISO 9001:2008 Certified

International Journal of Engineering and Innovative Technology (IJEIT)

Volume 10, Issue 11, May 2021

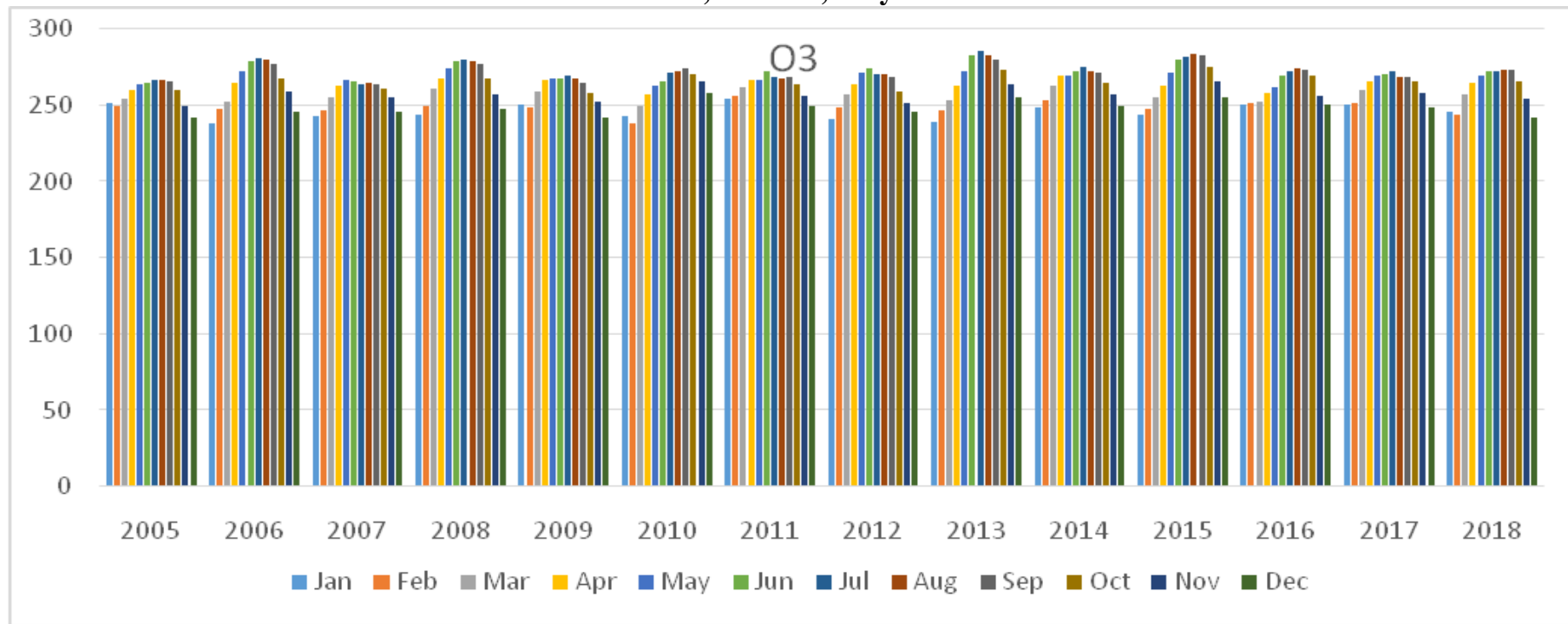

Fig. 5: Monthly concentration of Ozone. June recorded the highest annual concentration in 2011 and 2012 while Augustrecorded the highest concentration in 2015 and 2016.

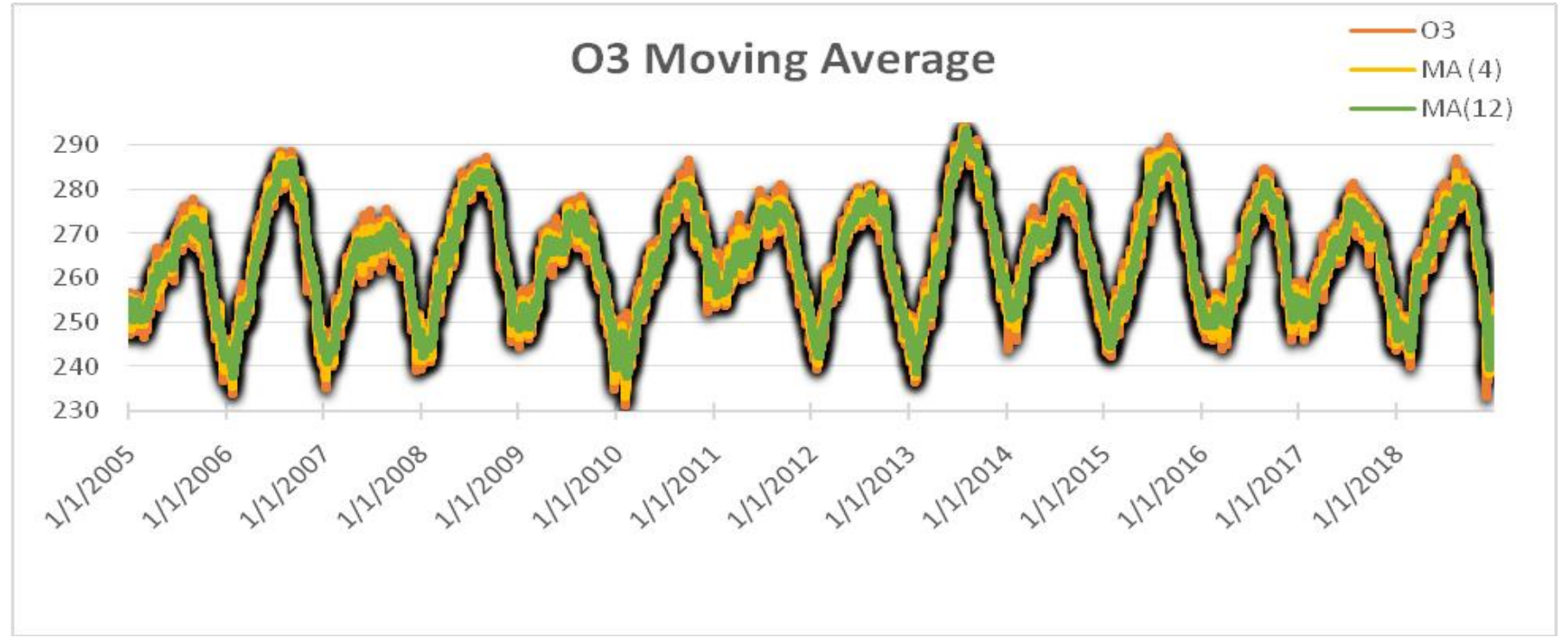

Fig. 7: Moving average MA (4) and MA (12) of ozone

For moving average Ma (4) and Ma (12) showed a dome shape plot. From fig 6 there is a seasonal fluctuations of ozone indicating highest peaks around July- August in the years 2013, 2006, 2016 and 2018 while the minima points were witnesses between the months of January, February and December.Moving average (12), which had removed the noise, still showed a sinusoigdalplots with both regularity and seasonality.

\section{CONCLUSION}

From this study, the range of ozone all through the sampled years was small,it was 9.52DU. The annual variation of ozone was consistent allthrough the study years. They all had an annual pattern of a dome shape,peaking around July -August. The concentration of ozone did not show a decreasing trend like in most developed countries, most of which are recording declining criteria pollutants. The implication shows that not much has been done to reduce atmospheric concentraion of ozoneover Nigeria.

\section{REFERENCES}

[1] Ana G.R., "Air Pollution in the Niger Delta Area: Scope, Challenges and Remedies", The Impact of Air Pollution on Health, Economy, Environment and Agricultural Sources, InTech Open limited, pp: 181-198, 2011.

[2] Kayode, S. J., \& Kamson, F., "Air Pollution by Carbon Monoxide (CO) Poisonous Gas in Lagos Area Southwestern Nigeria", Atmospheric and Climate Sciences Vol.3 No.4 pp:510-514, 2013.

[3] Marais E.A., Jacob D.J., Wecht K, Lerot C., Zhang L., Yu K., Kurosu T.P. K., Chance K., \& Sauvage B., "Anthropogenic emissions in Nigeria and implications for atmospheric ozone pollution: A view from space", 
ISSN: 2277-3754

ISO 9001:2008 Certified

International Journal of Engineering and Innovative Technology (IJEIT)

Volume 10, Issue 11, May 2021

Atmospheric Environment, Volume 99, December 2014, pp:32-40,2014.

[4] Obanya H.E., Amaeze N. H., Togunde O. \& Otitoloju A. A., "Air Pollution Monitoring around Residential and Transportation Sector Locations in Lagos". Journal of Health \& Pollution Vol. 8, No. 19, September 2018, pp:110,2018 .

[5] Olowoporoku A., Longhurst J. \& Barnes, J., "Framing Air Pollution as a Major Health Risk in Lagos, Nigeria", Conference in Air Pollution XX, Boston: WIT Press, ISBN-10: 9781845645823, pp.: 479-486, 2012.

[6] Zhou Y., Mao H., Demerjian K.,Hogrefe C.,\& Liu J., "Regional and Hemispheric Influences on Temporal Variability in Baseline Carbon Monoxide and Ozone over the Northeast US", Atmos Environ pp: 309-324,2017.

[7] IAMAT, "Nigeria general health risks: air pollution", International association for Medical assistance to travelers, pp:1-3,2020.

[8] Wnyonyi, S., "Dealing with air polution in Nigeria the Borgen project", 7 October 2019, https://borgenproject.org/wpcontent/uploads/The_Borgen_ Project_Logo_small.j 